\title{
Autopsy findings in COVID-19-related deaths: a literature review
}

\author{
Aniello Maiese $^{1}$ - Alice Chiara Manetti ${ }^{1} \cdot$ Raffaele La Russa $^{2} \cdot$ Marco Di Paolo $^{1} \cdot$ Emanuela Turillazzi $^{1} \cdot$ Paola Frati $^{2}$. \\ Vittorio Fineschi ${ }^{2}$ (D)
}

Accepted: 3 September 2020 / Published online: 7 October 2020

(C) The Author(s) 2020

\begin{abstract}
Although many clinical reports have been published, little is known about the pathological post-mortem findings from people who have died of the novel coronavirus disease. The need for postmortem information is urgent to improve patient management of mild and severe illness, and treatment strategies. The present systematic review was carried out according to the Preferred Reporting Items for Systematic Review (PRISMA) standards. A systematic literature search and a critical review of the collected studies were conducted. An electronic search of PubMed, Science Direct Scopus, Google Scholar, and Excerpta Medica Database (EMBASE) from database inception to June 2020 was performed. We found 28 scientific papers; the total amount of cases is 341 . The major histological feature in the lung is diffuse alveolar damage with hyaline membrane formation, alongside microthrombi in small pulmonary vessels. It appears that there is a high incidence of deep vein thrombosis and pulmonary embolism among COVID-19 decedents, suggesting endothelial involvement, but more studies are needed. A uniform COVID-19 post-mortem diagnostic protocol has not yet been developed. In a time in which international collaboration is essential, standardized diagnostic criteria are fundamental requirements.
\end{abstract}

Keywords COVID-19 $\cdot$ Autopsy $\cdot$ Findings $\cdot$ Pathophysiology

\section{Introduction}

The outbreak of the new SARS-CoV-2 (severe acute respiratory syndrome coronavirus 2) infection has spread all over the world [1], and on 11 March 2020, the World Health Organization declared it a pandemic [2]. COVID-19 (coronavirus disease 2019) has become a challenge for all health care authorities due to an increasing number of severely ill patients, which overloads intensive care units.

SARS-CoV-2 infection causes the release of a significant amount of pro-inflammatory cytokines that aggravate interstitial pneumonia and acute respiratory distress syndrome (ARDS) [3-6]. This clinical picture evolves into viral sepsis

Vittorio Fineschi

vittorio.fineschi@uniroma1.it

1 Department of Surgical Pathology, Medical, Molecular and Critical Area, Institute of Legal Medicine, University of Pisa, 56126 Pisa, PI, Italy

2 Department of Anatomical, Histological, Forensic and Orthopedic Sciences, Sapienza University of Rome, Viale Regina Elena 336, 00161 Rome, RM, Italy with prominent hypercoagulability and multiorgan dysfunction [7-11].

Autopsy findings are crucial to gaining a better understanding of how this infection affects the human body, similar to how these findings are important to understanding other infectious diseases [12-14]. Histopathological evidence of damage to the surface layers of airway epithelial cells and massive lung involvement with diffuse alveolar damage (DAD) and microvascular thrombi have been reported $[15,16]$.

The aim of this paper is to collect the currently available pathological data on COVID-19 and review the international literature on the postmortem findings of patients with COVID19. A distinction between minimally invasive autopsy and complete autopsy is also made.

\section{Methods}

The present systematic review was carried out according to the Preferred Reporting Items for Systematic Review (PRISMA) standards [17]. A systematic literature search and a critical review of the collected studies were conducted. An electronic search of PubMed, Science Direct Scopus, Google Scholar, 
and Excerpta Medica Database (EMBASE) from database inception to June 2020 was performed. The search terms were "COVID-19", "SARS-CoV-2", "autopsy", "postmortem", "biopsy", and "histology" in the title, abstract, and keywords. The bibliographies of all located papers were examined and crossreferenced to further identify relevant literature. A methodological appraisal of each study was conducted according to the PRISMA standards, including an evaluation of bias. The data collection process included study selection and data extraction. Three researchers (RLR, PF, and MDP) independently examined the papers with titles or abstracts that appeared to be relevant and selected those that analyzed postmortem COVID-19 findings. Disagreements concerning eligibility among the researchers were resolved by consensus. Preprint articles were included. Data extraction was performed by two investigators $(\mathrm{AM}, \mathrm{ACM})$ and verified by other investigators (VF, ET). This study was exempt from institutional review board approval, as it did not involve human subjects. Only papers in English were included in the search, except for one study in which only the abstract was available in English.

\section{Results}

A review of the titles and abstracts as well as a manual search of the reference lists were carried out. The reference lists of all identified articles were reviewed to find missed literature. This search identified 125 articles, which were then screened based on their abstract. The resulting 125 reference lists were screened to exclude duplicates, which left 48 articles for further consideration. In addition, non-English papers were excluded, and the following inclusion criteria were used: (1) original research articles, (2) reviews and mini-reviews, and (3) case reports/series. These publications were carefully evaluated, taking into account the main aims of the review. This evaluation left 28 scientific papers (8 concerning minimally invasive autopsies, and 20 concerning complete autopsies) comprising original research articles, case reports/series, reviews, and mini-reviews. Figure 1 illustrates our search strategy. We divided the results into two groups: minimally invasive autopsies and complete autopsies (Table 1).

\section{Minimally invasive autopsies}

As previously mentioned, the first work about the pathological findings of COVID-19 were based on biopsies and partial autopsies.

In February 2020, Xu et al. [15] described the case of a man who experienced 14 days of progressive respiratory symptoms and died due to sudden cardiac arrest during an episode of respiratory failure (oxygen saturation 60\%). Core biopsies were conducted, and the lung, heart, and liver were sampled. The lungs showed early DAD with hyaline membranes and edema, the interstitium was infiltrated by lymphocytes, and pneumocytes manifested cytopathic changes (multinucleated syncytial cells), suggesting viral damage. No peculiar alterations of the myocardium were observed, except moderate interstitial mononuclear infiltrate. The liver tissue was characterized by microvesicular steatosis, a nonspecific feature that could not be directly correlated to the virus. The authors suggested that the overactivation of Tcells could be partially responsible for the immune system damage.

Zhang et al. [16] performed postmortem transthoracic needle biopsies of the lungs in a 72-year-old patient who died of respiratory insufficiency due to COVID-19. Lung tissue showed organizing DAD with fibrinous exudate into the alveoli and chronic inflammatory infiltrates and fibrosis of the interstitium. SARS-CoV-2-specific immunostaining revealed viral particles in the alveolar epithelium that were almost undetectable on the interstitium and vessel walls.

Dolhnikoff et al. [18] performed ultrasound-based minimally invasive autopsies of ten deceased patients with COVID-19 in São Paulo. The authors sampled the brain, lungs, heart, liver, spleen, kidneys, skeletal muscle, and skin. Histology revealed diffuse exudative and proliferative DAD alongside foci of alveolar hemorrhage. There was also little lymphocytic infiltration, and the epithelium of the alveoli and small airways showed viral cytopathic damage. Fibrin microthrombi were observed in small pulmonary arterioles of the lungs, glomeruli, and derma. In addition, there were many megakaryocytes within the pulmonary capillaries.

$\mathrm{Li}$ et al. [19] analyzed the three-dimensional histology reconstruction obtained from lung tissue samples of patients who died because of COVID-19. Their work emphasized the presence of megakaryocytes alongside fibrin aggregates in the pulmonary small vessels and viral cytopathic changes in pneumocytes.

In May 2020, Yao et al. [20] published a case series regarding minimally invasive autopsies of three COVID-19 decedents. Unfortunately, only the abstract of the paper is available in English. Nevertheless, it was included in our study as it could be useful for our purpose. The authors found hyaline membrane formation into the alveoli, with serous and fibrin exudate, and inflammatory infiltration was mainly represented by macrophages and lymphocytes (CD4-positive Tcells). Few multinucleated giant cells were also present. A peculiar finding was congestion and edema of the lung capillaries with modest infiltration of monocytes and lymphocytes and hyaline thrombi in the lumen. Focal hemorrhages were also observed. Immunohistochemistry and PCR (Polymerase Chain Reaction) analysis confirmed the presence of SARS-CoV-19 in the macrophages and alveolar epithelia.

The histopathological findings of lung, liver, and heart core biopsies conducted on four deceased COVID-19 patients were described by Tian et al. [21]. The pulmonary tissue was characterized by $\mathrm{DAD}$ with hyaline membrane formation and type II pneumocyte activation. They also observed fibroblastic 
Fig. 1 An appraisal based on titles and abstracts as well as a hand search of reference lists was carried out. The resulting 125 references were screened to exclude duplicates, which left 48 articles for further consideration. In addition, non-English papers were excluded and the following inclusion criteria were used: (1) original research articles, (2) reviews and mini-reviews, and (3) case report/series. These publications were carefully evaluated taking into account the main aims of the review. This evaluation left 28 scientific papers ( 8 concerning minimally invasive autopsies, 20 concerning complete autopsies), distributed as original research articles, case report/series, reviews, and minireviews

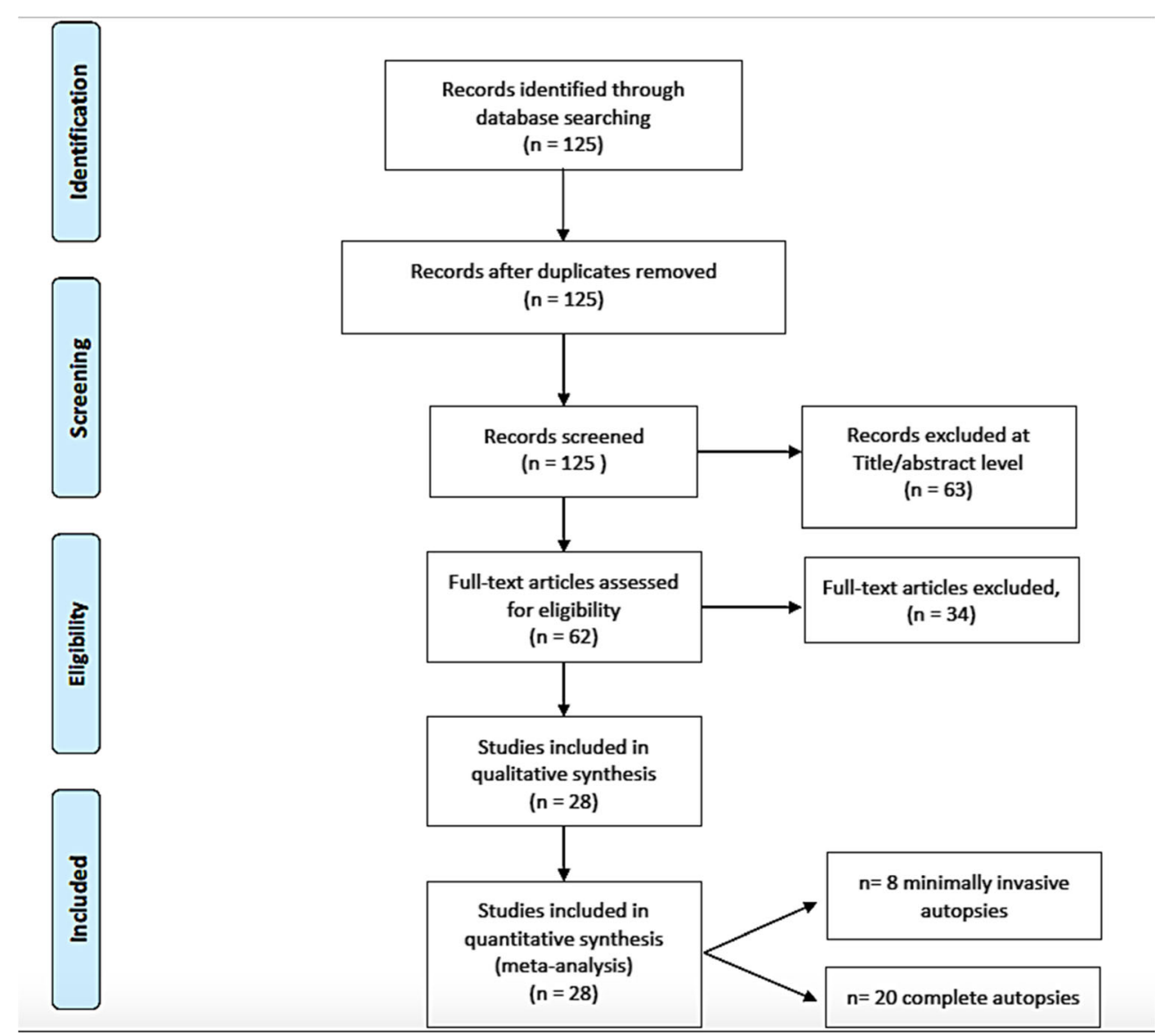

proliferation and fibrin cluster formation. The pulmonary vessels were congested, and some alveoli lacked blood cells. The alveolar septa were thick due to fibrin and inflammatory infiltration (mononuclear cells). The liver tissue, as well as the myocardium, did not manifest pathological features traceable to COVID-19 damage.

Duarte-Neto et al. [22] performed 10 ultrasound-guided minimally invasive autopsies of patients who tested positive for SARS-CoV-2 infection. The lung parenchyma showed exudative/proliferative DAD, cytopathic respiratory epithelium damage, and an abundance of alveolar megakaryocytes. Fibrinous microthrombi were found in the alveolar arterioles, as well as in various other organ vessels (glomeruli, testis, liver, and heart). Aside from comorbidity-associated and shock-related findings, they also found perivascular mononuclear infiltration of the skin in eight cases, two cases of myositis and two cases of orchitis with diffuse small vessel endothelial changes.

An autopsy case report was published in the Revista Espanola de Patología [23] regarding a deceased 54-year-old man who was hospitalized because of dyspnea, cough, fever, and chills. The nasopharyngeal swab was positive for SARS$\mathrm{CoV}-2$. In situ sampling was performed to reduce the risk of contamination. The lungs appeared heavy, firm, and congested. Histological analysis showed both exudative and organizing DAD, platelet thrombi in small and medium vessels, slight septal thickening, and capillary congestion. There were also rare mononuclear inflammatory infiltrates and pneumocyte hyperplasia with cytopathic changes. The kidney had cortical necrosis.

In May, Magro et al. [24] reported five cases of lung and/or skin microvascular injury in patients who tested positive for SARS-CoV-2. In two cases, minimally invasive autopsies were conducted. The main histological feature was a pauciinflammatory septal capillary injury with significant septal capillary fibrin deposition, alongside neutrophil infiltration of the septa. DAD with hyaline membranes and type II pneumocyte hyperplasia were not the main characteristics. In addition, the authors found relevant signs of systemic activation of the complement cascade, both in the lungs and skin biopsies. A notable finding was the presence of both SARSCoV-2 spike glycoproteins and C4d and C5b-9 in the alveolar septa.

\section{Complete autopsies}

$\mathrm{Su}$ et al. [25] published a case series of 26 autopsies at the beginning of April 2020, focusing mainly on renal findings. The main histological feature was acute tubule injury (ATI); in two cases, there was also acute pyelonephritis. In one of these 
Table 1 Review of the literature on COVID-19 related-death autopsies, what kind of examination and analysis has been performed

\begin{tabular}{|c|c|c|c|c|c|c|c|}
\hline & $\mathrm{N}^{\circ}$ of Cases & $\begin{array}{l}\text { Complete } \\
\text { autopsy }\end{array}$ & $\begin{array}{l}\text { Minimally } \\
\text { invasive } \\
\text { autopsy }\end{array}$ & Histology & Immunohistochemistry & $\begin{array}{l}\text { Electron } \\
\text { microscopy }\end{array}$ & $\begin{array}{l}\text { Post-mortem } \\
\text { imaging }\end{array}$ \\
\hline $\mathrm{Xu}$ et al & 1 & - & 1 & 1 & Not reported & Not reported & Not reported \\
\hline Zhang et al & 1 & - & 1 & 1 & 1 & Not reported & Not reported \\
\hline Dolhnikoff et al & 10 & - & 10 & 10 & Not reported & Not reported & Not reported \\
\hline Yao et al & 3 & - & 3 & 3 & 3 & 3 & Not reported \\
\hline Tian et al & 4 & - & 4 & 4 & 1 (in a case with CLL) & Not reported & Not reported \\
\hline $\begin{array}{l}\text { Duarte-Neto } \\
\text { et al }\end{array}$ & 10 & - & 10 & 10 & 10 & Not reported & Not reported \\
\hline $\begin{array}{l}\text { Ramon y Cajal } \\
\text { Hospital }\end{array}$ & 1 & - & 1 & 1 & 1 & Not reported & Not reported \\
\hline Magro et al & $\begin{array}{l}2 \text { ( } 5 \text { including in life } \\
\text { biopsies) }\end{array}$ & - & 2 & 2 & 2 & Not reported & Not reported \\
\hline Su et al & 26 & 26 & - & 26 & 26 & 26 & Not reported \\
\hline Barton et al & 2 & 2 & - & 2 & 2 & Not reported & $\begin{array}{l}2 \text { (full body a-p } \\
\text { radiographs) }\end{array}$ \\
\hline Grimes et al & 2 & 2 & - & 2 & Not reported & 2 & Not reported \\
\hline Varga et al & $\begin{array}{l}2 \text { (3 including } 1 \\
\text { intestine } \\
\text { resection) }\end{array}$ & 2 & - & 3 & Not reported & 1 & Not reported \\
\hline Bradley et al & 12 & 5 & 7 & 12 & Not reported & 12 & Not reported \\
\hline $\begin{array}{l}\text { Paniz-Mondolfi } \\
\text { et al }\end{array}$ & 1 & $\begin{array}{l}\text { Not } \\
\quad \text { specified }\end{array}$ & Not specified & 1 & Not reported & 1 & Not reported \\
\hline Lacy et al & 1 & 1 & - & 1 & Not reported & Not reported & Not reported \\
\hline Konopka et al & 1 & 1 & - & 1 & Not reported & Not reported & Not reported \\
\hline Prilutskiy et al & 4 & 4 & - & 4 & 4 & Not reported & Not reported \\
\hline Yan et al & 1 & 1 & - & 1 & 1 & 1 & Not reported \\
\hline Fitzek et al & 1 & 1 & - & 1 & Not reported & Not reported & 1 (РMCT) \\
\hline Edler et al & 80 & 80 & - & 12 & Not reported & Not reported & 80 (PMCT) \\
\hline Bryce et al & 67 & 67 & - & 25 & Not specified & $\begin{array}{l}\text { Not } \\
\quad \text { specified }\end{array}$ & Not reported \\
\hline Menter et al & 21 & 17 & 4 & 21 & 11 & 2 & Not reported \\
\hline Remmelink et al & 17 & 17 & - & 17 & 17 & Not reported & Not reported \\
\hline Wichmann et al & 12 & 12 & - & 12 & 12 & $\begin{array}{l}12 \text { (only } \\
\text { lung } \\
\text { samples) }\end{array}$ & 10 (РMCT) \\
\hline Schaller et al & 10 & 10 & - & 10 & Not reported & Not reported & Not reported \\
\hline Aguiar et al & 1 & 1 & - & 1 & 1 & Not reported & 1 (РMCT) \\
\hline Fox et al & 10 & 10 & - & 10 & 10 & 10 & Not reported \\
\hline Carsana et al & 38 & 38 & - & 38 & $\begin{array}{l}\text { On the most representative areas } \\
\text { of randomly selected cases }\end{array}$ & 10 & Not reported \\
\hline Total & 341 & 297 & 44 & 232 & 101 & 80 & $\begin{array}{l}94(2 \mathrm{RX}, 92 \\
\text { PMCT) }\end{array}$ \\
\hline
\end{tabular}

two cases, there was evidence of inflammatory cell infiltration of an arcuate artery alongside red cell aggregation in the peritubular and glomerular capillaries. Some lymphocytic infiltrate areas were also observed. Through electron microscopy, the authors identified some viral particles in the renal epithelium and podocytes. Immunohistochemistry did not reveal specific accumulation of inflammatory cells and confirmed the presence of red cell aggregates in the microvessel lumen.
Barton and colleagues [26] reported the findings of two complete autopsies of postmortem SARS-CoV-2-positive decedents who died just before or some hours after hospital admission. While alive, both patients had fever and shortness of breath, but only one of them also had a cough. Postmortem nasopharyngeal swabs were positive for SARS-CoV-2 (rRT$\mathrm{PCR}$ ); in one case, the lung parenchyma swab was also positive. Postmortem radiography showed bilateral pulmonary opacities, and macroscopic examination showed heavy, red- 
maroon lungs. Microscopic examination revealed acute DAD with hyaline membranes and thrombi within the small pulmonary arteries in one case and foci of aspiration pneumonia in the other case. Immunohistochemistry also demonstrated the presence of CD3-, CD4-, and CD8-positive T cells, plus numerous macrophages in the patient with focal pneumonia. The decedent who showed DAD microscopically was determined to have died from COVID-19; in the other case, COVID-19 was considered an "other significant condition".

Grimes et al. [27] described the autopsy findings of two patients who died from COVID-19 at their institution. In both cases, pulmonary thromboembolism was found, causing occlusion of the right main pulmonary artery in one case and both main pulmonary arteries in the other case. Histology confirmed this finding, and deep venous thrombosis was present in both cases. Electron microscopy showed viral inclusions within the pneumocytes.

Varga et al. [28] reported the cases of three patients with COVID-19. Autopsies were performed in two cases; the third patient was still alive, so only histology of a part of the small intestine, which was resected due to mesenteric ischemia, was performed. The aim of this study was to demonstrate endothelial damage to various organs. The lungs of the two decedents showed signs of DAD and ARDS. In all cases, lymphocytic endotheliitis was seen in various organs; in particular, in one case, the lung, heart, kidney, and liver, and the myocardium showed acute infarction, while no myocarditis was observed; in another case, there was endotheliitis of the pulmonary, heart and small bowel vessels with ischemic necrosis of the small intestine mucosa. In the patient who was still alive, the small intestine showed mucosal ischemic necrosis along with endotheliitis. One of the two decedents had undergone kidney transplantation, and the transplanted organ showed viral inclusion in the endothelial cells by electron microscopy.

The findings of twelve autopsies, including both complete and minimally invasive autopsies, of deceased COVID-19 patients were described by Bradley et al. [29]. The lungs were generally heavy and edematous; one patient also showed intraparenchymal hemorrhages, and two patients had pulmonary emboli. Histological findings were DAD at the acute and organizing stage with reactive type II pneumocytes. In two cases, acute bronchiolitis and bronchopneumonia were also observed. Viral particles within the cells of the lungs, trachea, kidney, and large intestine were observed by electron microscopy. In addition to nonspecific chronic changes of various organs, the authors reported acute tubular damage in one case and periportal lymphocytic inflammation of the liver in some cases.

Concerning central nervous system involvement, PanizMondolfi et al. [30] reported the histological and electron microscopy findings of a man who was admitted to their hospital because of fever, confusion and two falls at home. No other suggestive symptoms were described, but the nasopharyngeal swab test for SARS-CoV-2 was positive. During hospitalization, the patient gradually decompensated and then died after eleven days. Viral particles were seen in the frontal lobe of his brain as well as within the brain's endothelial cells. A real-time PCR test of the brain tissue also confirmed the presence of SARS-CoV-2.

A description of the postmortem investigations performed on the body of a 58-year-old woman who suddenly died of COVID-19 was provided by Lacy et al. [31]. Fever and dyspnea were reported in the week before death. She also had important comorbidities (type 2 diabetes mellitus, hypertension, obesity, asthma, chronic lower extremity ulcers). She was found in her apartment less than one day after her death, which occurred while she was in quarantine. A scene investigation and autopsy were performed, and COVID-19 was suspected due to her symptoms. The lungs appeared heavy, firm, and edematous, with some hemorrhage areas and thick mucus into the airways, and the mediastinal lymph nodes were dimensionally augmented. Histologically, the pulmonary parenchyma was confirmed to be edematous and presented hyaline membranes alongside mononuclear infiltrate of the alveolar septae. Desquamation of hyperplastic pneumocytes and multinucleated cells was also observed, as well as foamy macrophages. Focal alveolar hemorrhages were another microscopic finding. The other organs did not manifest peculiar alterations: the hepatic tissue was congested with central lobular paleness, and the kidneys showed global glomerular and mesangial sclerosis. Bronchi swabs, collected during autopsy, were positive, so her death was declared to be due to ARDS related to COVID-19.

Konopka et al. [32] provided a description of the postmortem lung findings of a 37-year-old man who had a history of asthma and type 2 diabetes mellitus. He was admitted to their hospital because of fever, cough, and myalgia. The swab test for SARS-CoV-2 was positive. Despite treatment, he worsened, and after nine days of hospitalization, he suddenly manifested cardiogenic collapse and died. The autopsy revealed heavy lungs with mucus within the airways, which was confirmed by histology to be paucicellular mucus. As expected, histology also showed chronic asthmatic alterations of the airways. There was also DAD, fibrinous airspace exudate, and rare fibrin thrombi within the small pulmonary vessels.

Prilutskiy et al. [33] conducted autopsies (restricted to the chest and abdomen) on four patients who died because of COVID-19. The aim of their study was to evaluate if hemophagocytosis was detectable through immunohistochemistry (staining for CD163) and so, in addition to the lung tissue, they also sampled the mediastinal and pulmonary hilar lymph nodes, liver, spleen, and bone marrow. The lungs showed acute exudative DAD. The lymph nodes were enlarged, and in three to four cases, the lymph nodes contained hemophagocytic histiocytes. Only in one case was the spleen enlarged, and red pulp hemorrhage was seen histologically alongside hemophagocytic histiocytes. In all cases, the 
liver did not present any peculiar findings. The bone marrow was characterized by myeloid hyperplasia, with no hemophagocytosis.

The case of a 44-year-old obese Hispanic woman who died of COVID-19 was reported by Yan et al. [34]. She was admitted with respiratory symptoms, but during hospitalization, she developed acute respiratory distress syndrome and Takotsubo cardiomyopathy, which clinicians suspected to be related to viral myocarditis. On the sixth day of hospitalization, she died from multiorgan failure. Autopsy revealed heavy lungs with signs of pleuritis and enlarged peribronchial lymph nodes. Histologically, the authors observed edema, an area of infarction, DAD with hyaline membranes, and pneumocyte cytopathic damage. Viral inclusions were observed by electron microscopy. Grossly, the right atrium appeared streaked, and the right ventricle was dilated. Histologically, the heart showed myxoid edema, myocyte hypertrophy, and focal nuclear pyknosis. Interestingly, CD45positive lymphocytes were found in the left ventricular papillary muscle. The kidneys appeared normal on gross examination, but histologically, they had peritubular congestion and focal acute tubular damage.

A peculiar case was described by Fitzek et al. [35]: a 59year-old German man experienced dizziness and a cough during a journey to Egypt. He was admitted to a local private clinic, but after some days of hospitalization, he died. The man's body was then embalmed and transferred to Germany, where Fitzek and colleagues performed postmortem computed tomography (PMCT) and then an autopsy. The PMCT showed multifocal reticular consolidation alongside bilateral moderate pleural effusions. On gross examination, the lungs appeared firm and edematous. Signs of hemorrhagic tracheobronchitis were also recognized. Microscopically, there was DAD with diffuse hyaline membranes, alongside microthrombi and mild lymphocyte infiltration. The autopsy also showed congestive cardiomyopathy with cor adiposum as a pre-existing comorbidity.

Edler et al. [36] autopsied 80 deceased patients who tested positive, ante- or postmortem, for SARS-CoV-19. In four cases, COVID-19 was not correlated with death, and there were no radiological or autoptic findings indicative of active infection. For those with pneumonia, on gross examination, the lungs appeared heavy, with a mosaic-like pattern on the surface with evident capillary drawing. The pulmonary tissue appeared solidified. In 32 cases, deep vein thrombosis was present (demonstrated to be fresh by microscopy), and 17 of these patients also showed pulmonary artery embolism (nine peripheral, eight fatal fulminant). Regarding the microscopy findings, unfortunately, only twelve cases were investigated histologically at the time the results were published. In eight cases, DAD was found, characterized by the presence of active type II pneumocytes and fibroblasts in the context of exudative edema and hyaline membrane. There was also fibrosis and squamous metaplasia in advanced stages. The pulmonary vessel endothelia did not show vasculitis alterations, but the small arteries had conspicuous lymphocytes and plasma cell infiltration. In the remaining four cases, there was granulocyte focal confluent bronchopneumonia. Regarding other microscopic findings, the liver, kidneys, or intestine showed shock-related changes (four cases), as well as other chronic alterations.

The autopsy and microscopic findings of 67 cases were described in detail by Bryce et al. [37]. In summary, the lung parenchyma appeared variously altered, from patchy to diffusely consolidated, with acute DAD alongside hyaline membrane formation. Immunohistochemistry revealed thrombi within the small and medium pulmonary arteries. In 15 cases, the epicardium showed mononuclear and CD4-positive lymphocyte infiltrate, which was associated with thrombi in three cases. The kidney had acute tubular injury in six cases. Microthrombi and acute infarction of the brain were also observed.

Menter et al. [38] described the features of various organs in 21 autopsies (17 complete, and the remainder partial autopsies) of SARS-CoV-2 positive subjects. All of them had previous comorbidities (hypertension and obesity were the most common), and 14 of them took renin-angiotensin-aldosterone-system (RAAS)-modulating drugs. The lungs appeared heavy, firm, and congested; the parenchyma features were varied: some looked patchy, some had consolidations, and some others showed suppurative bronchopneumonia infiltrates. Histologically, the main feature was exudative DAD, while in eight cases, DAD was in the proliferative stage. Ten patients also had superimposed bacterial bronchopneumonia. Capillary congestion was another predominant feature, as well as edema and alveolar hemorrhage. Immunohistochemistry for fibrin was performed in eleven cases, and it showed microthrombi in the alveolar capillaries in five cases; the presence of fibrin in the capillaries was also confirmed by electron microscopy (performed in two cases). The authors also described the findings of other organs in detail: in particular, they highlighted that senile cardiac amyloidosis was four times more prevalent in these autopsies than in examinations conducted in their institute between 2018 and 2019, which was significant. Shock-related signs were common, the kidney showed diffuse acute tubular injury and, in some cases, disseminated intravascular coagulation was seen.

Remmelink and colleagues [39] described the pathological findings of 17 autopsies conducted on COVID-19 patients who died of respiratory or multiorgan failure ( 9 and 8 , respectively). The lungs were heavy and firm with hemorrhage areas; in two cases, thrombi in the large pulmonary arteries were seen on gross examination. Histologically diffuse exudative $\mathrm{DAD}$ was the main feature (15/17), alongside late-stage DAD, microthrombi in small lung arteries (11/17), and lung infarcts (4/17). Regarding other organs, they found one case of 
ischemic enteritis and two cases of acute myocardial infarction. The kidneys were often enlarged with a pale cortex, petechiae, and the presence of hemosiderin in the lumen of the tubules. The authors also investigated the presence of SARS-CoV-2 in various tissues through immunohistochemistry (anti-SARS-nucleocapsid protein antibody stain, only lung tissue) and rRT-PCR the presence of SARS-CoV-2 in various tissues. The new coronavirus was detected in the lungs of 11/17 cases and in at least one organ of each patient. In particular, SARS-CoV-2 was also detected in the brain (9/11 — not all the autopsies included brain evisceration), heart (14/17), liver (14/17), spleen (11/17), bowel (14/17), and kidney $(10 / 17)$, and in $8 / 17$ cases, the virus was in all the tested organs.

A prospective cohort study conducted by Wichmann et al. [40] collected data from twelve complete autopsies of outpatients and inpatients who tested positive for SARS-CoV-2. PMCT was performed in ten cases and showed reticular infiltrations and consolidating infiltrates; the ground-glass opacities were comparable with those on the antemortem $\mathrm{CT}$ images. The authors revealed that seven patients had bilateral deep vein thrombosis, four of whom also had massive pulmonary embolism, which was their cause of death. The total incidence of DVT was $58 \%$. Grossly, the lungs appeared heavy, firm and congested, with pleurisy and patchy patterns on the surface and on the cutting surface. The gross examination of other organs did not reveal significant features, except for splenomegaly. Histological examination of the lung showed DAD (eight cases) with microvascular thrombi, capillary congestion, and edema. When bacterial superinfection was present, granulocytic infiltration was observed under the microscope. The other organs showed shockrelated changes.

A research letter was published on 21 May 2020 by Schaller et al. [41] regarding the postmortem examinations of ten SARSCoV-2-positive patients who died in a hospital setting. All of them had at least one pre-existing pathology, such as cardiovascular diseases (most frequent), chronic kidney failure, obesity, etc. The main histologic feature was different phases of DAD, involving, in particular, the middle and lower pulmonary lobes. The extrapulmonary findings were fibrosis and periportal lymphoplasmacellular infiltration of the liver, mild lymphocytic myocarditis in one case, and signs of epicarditis in another case.

Aguiar et al. [42] reported a case of a forensic autopsy of a woman found dead in her flat. She had a cough during the previous days, but the diagnosis of COVID-19 was made after death (positive tracheobronchial swab). The only known comorbidity was obesity (body mass index BMI $61.2 \mathrm{~kg} / \mathrm{m}^{2}$ ). PMCT was performed and showed bilateral ground-glass opacities and panlobar consolidations. On gross examination, the lungs were heavy and firm and presented hemorrhagic edema. Microscopically, the lung tissue showed edema, early stage DAD with hyaline membranes, and intra-alveolar hemorrhages. Viral inclusions were not seen. In the interstitium, there were CD3-positive T cells and megakaryocytes. In addition to these pulmonary features, autopsy revealed only chronic tracheitis and hepatic microabscesses. This case is significant because the woman was young and did not receive any medical treatment. In the authors' opinion, the cause of death was related to COVID-19 pulmonary alterations and high fever.

Fox et al. [43] collected data from ten autopsies of African American decedents. For all subjects, COVID-19 was stated as the cause of death. The lungs were heavy in all patients except for one who showed diffuse edema and firm parenchyma. Patchy hemorrhage was visible after fixation. The authors reported cardiomegaly and right ventricular dilatation as other significant macroscopic findings. Histologically, the main feature was DAD in different phases, predominantly (seven cases) between the exudative and proliferative phases. Except for one patient, all patients had evidence of pulmonary hemorrhage. Electron microscopy revealed cytomegalic type 2 pneumocytes with enlarged nuclei and eosinophilic nucleoli desquamated into the alveolar space. The decedents who did not receive ventilator support or who only received ventilator support for one day and had D-dimer elevation while alive also presented pulmonary microthrombi (two cases) with CD61 positivity. Immunohistochemistry also revealed the presence of CD4-positive and CD8-positive lymphocyte infiltration in the interstitial space and around bronchioles and blood vessels. In particular, some small vessels seemed to be surrounded by CD4-positive lymphocytes, with fibrin and platelet thrombi into the lumen. The authors highlighted the presence of CD61-positive megakaryocytes in the alveolar capillaries that seemed to produce platelets. In addition, cardiac histology showed single myocyte necrosis in the absence of proper necrosis areas or lymphocytic myocarditis.

Carsana et al. [44] described the postmortem examination findings of 38 deceased COVID-19 patients, focusing on pulmonary lesions. The lungs appeared heavy, edematous, and congested. The lung tissue histology revealed exudative and early or intermediate proliferative phases of DAD in all cases with focal features of interstitial, organizing, or acute fibrinous organizing pneumonia. In 33/38 cases, there were diffuse fibrin and platelet clots in the lumen of the peripheral small vessels of the lung. The authors stated reactive atypia and diffuse peripheral small vessel thrombosis were the characteristic histopathological findings. In addition, they also performed immunohistochemical analysis of selected cases, finding an abundance of CD45- and CD3-positive lymphocytes in the interstitial space, and CD68-positive macrophages predominantly in the alveoli. CD61-positive megakaryocytes were also abundant in the pulmonary capillaries (33/38 cases). Moreover, the lung specimens of ten cases underwent electron microscopy examination: some particles, which the authors assumed to be virions, were found within the both type 1 and type 2 pneumocytes in nine cases and were also localized 
in the macrophages in two cases. No viral particles were observed in the endothelial cells, despite fibrin and platelets being localized in the alveolar capillary lumen.

Table 2 summarizes the macro- and microscopic findings as described by the cited literature. The typical histological findings described in the literature are presented in Fig. 2.

\section{Discussion}

The need for postmortem information is urgent to improve patient management of mild and severe illness and therapy strategies. Nevertheless, since the initial phase of the pandemic in some countries, autopsies have been avoided [45, 46]. The first histopathologic reports of COVID-19-positive subjects were obtained from biopsies of alive patients, postmortem biopsies, surgical specimens, or transplanted organs [20, 21, 47-51]. Evidence on the safety of postmortem examinations, if properly conducted, and positive/suspected SARS$\mathrm{CoV}-2$ corpse management recommendations have appeared [52-58], and some studies about complete autopsies of deceased SARS-CoV-2-positive patients have been published.

At present, as the infection can still be considered a health care emergency in many countries, the pathophysiology of COVID-19 is only partially understood. Autopsy findings have a fundamental role, as was demonstrated in the past with other infectious diseases [14-16]. A literature review of the present evidence on the postmortem examinations of SARS$\mathrm{CoV}-2$-positive decedents highlights the main pathologic features of the disease.

The lungs generally appear heavy and edematous. Histologically, the most frequent pathological finding is both exudative and proliferative DAD in different stages, with hyaline membrane formation, inflammatory cell infiltration, and small vessel congestion. This feature bears a similarity to pulmonary damage due to SARS and MERS (Middle Eastern respiratory syndrome) [59-61]. There is also evidence that the new coronavirus SARS-CoV-2 causes endothelial dysfunction [62], which in turn could be responsible for multiorgan dysfunction [63]. Endothelial dysfunction could be explained by the expression of the receptor binding domain (RBD) on the SARS-CoV-2 surface [64], which binds ACE2 (angiotensin converting enzyme 2) receptors. ACE2 receptors are localized in many human tissues, including the endothelium [65, 66]. In addition, Magro et al. [24] found a possible correlation between the new coronavirus and complement activation.

An important feature that emerges from our data collection is the presence of thrombi in the microvessels of the lung, alongside the relatively high prevalence of deep vein thrombosis and subsequent pulmonary embolism, reported in particular by Edler et al. [36] and Wichmann et al. [40]. Some other works seem to agree with that evidence [67-69].
In our review, there is no evidence of peculiar findings in other organs correlated to COVID-19, even though Puelles et al. [70] demonstrated that the novel virus causes renal tropism, while Varga et al. [28] reported endotheliitis in various organs. In particular, although some clinical works underline possible cardiac involvement in patients with COVID-19 [3, $6,71]$, from our results, myocardium damage does not seem directly attributable to SARS-CoV-2 cytopathologic effects, but further studies are needed.

There are still not enough data to draw a complete picture of the pathophysiology of SARS-CoV-2 infection. Almost all the papers considered in this review focused on pulmonary macro- and microscopic alterations, and only a few pieces of information are given about the features of other organs and systemic findings, with few exceptions. Moreover, a clear postmortem diagnostic protocol for COVID-19 has not yet been drafted. The features that allow us to count a decedent as a SARS-CoV-2 related death remain unclear. Many recommendations about the safety of autopsy procedures have been published [52-58], but to the best of our knowledge, an essential and standardized postmortem diagnostic tool for COVID-19 has not been proposed. As a consequence, the studies we reviewed show procedural differences, i.e. postmortem imaging or immunohistochemistry was conducted in all cases. The absence of uniformity among studies is a potential limitation for comparisons of data not only in our research but also in further studies. A postmortem diagnostic tool is also essential to standardizing international data concerning population studies and health care management programs.

\section{Conclusion}

Despite attention to and investment in quantifying global burdens of disease, the diagnosis in the majority of COVID-19related deaths currently remain unclear. This seriously limits the veracity of the disease burden estimates and, more crucially, the capacity of local health systems to respond to the disease [72]. Nonetheless, different stages of DAD and the presence of thrombi in the small arteries of the lung seem to be the main pulmonary features of the novel coronavirus disease. It is possible to identify some similarities to pulmonary damage found in other coronavirus diseases, such as SARS and MERS [60,61]. The new coronavirus SARS-CoV-2 also seems to cause endothelial dysfunction [62], which in turn could be responsible for multiorgan dysfunction. It is important to emphasize the prevalence of deep vein thrombosis and pulmonary embolism, as well as microthrombi in the small pulmonary vessels. These features should be accurately taken into consideration by clinicians and researchers when implementing therapeutic strategies. Further autopsy studies are needed to expand this evidence and eventually highlight the pathognomonic signs of the disease. We also suggest that 


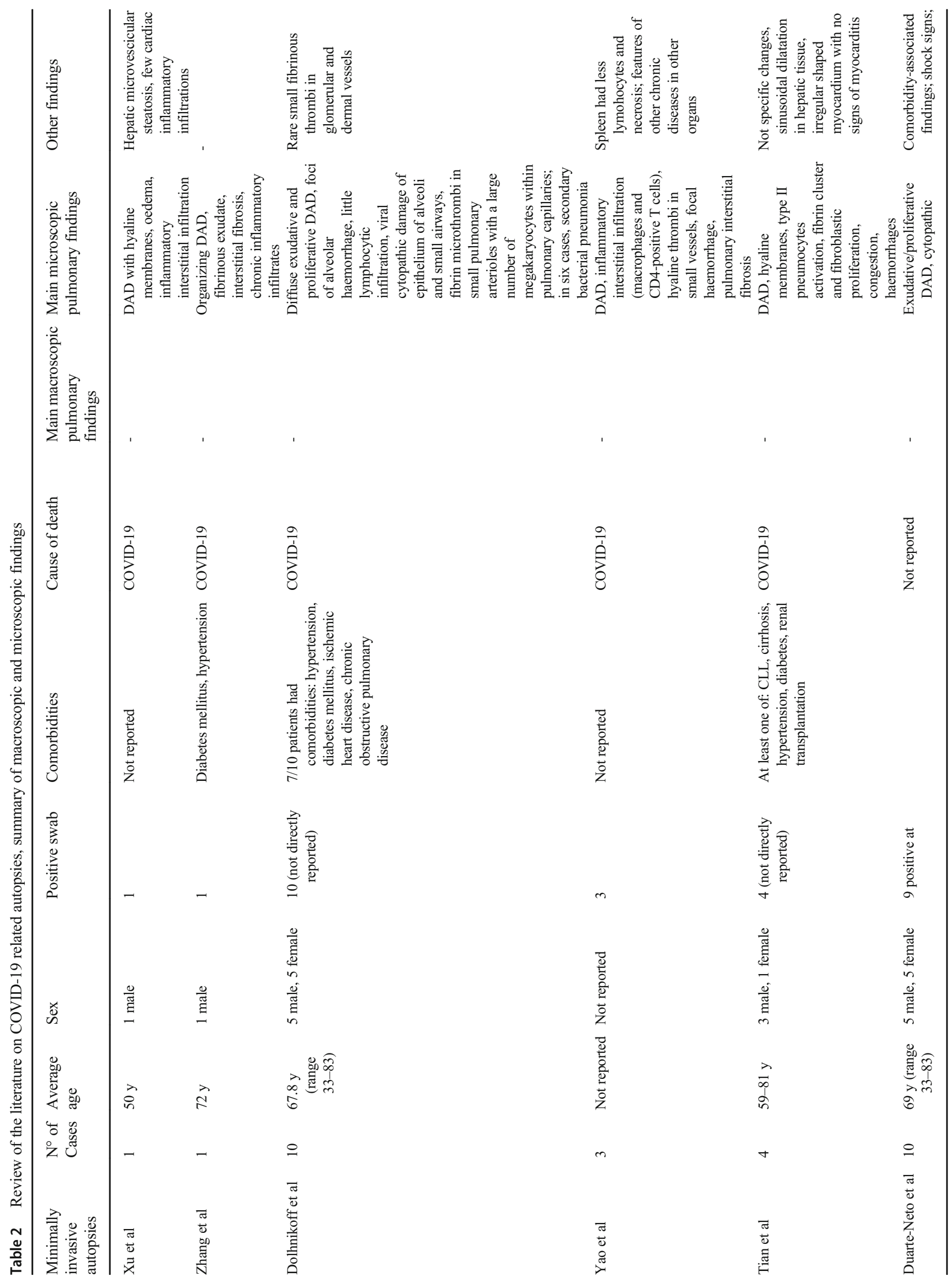




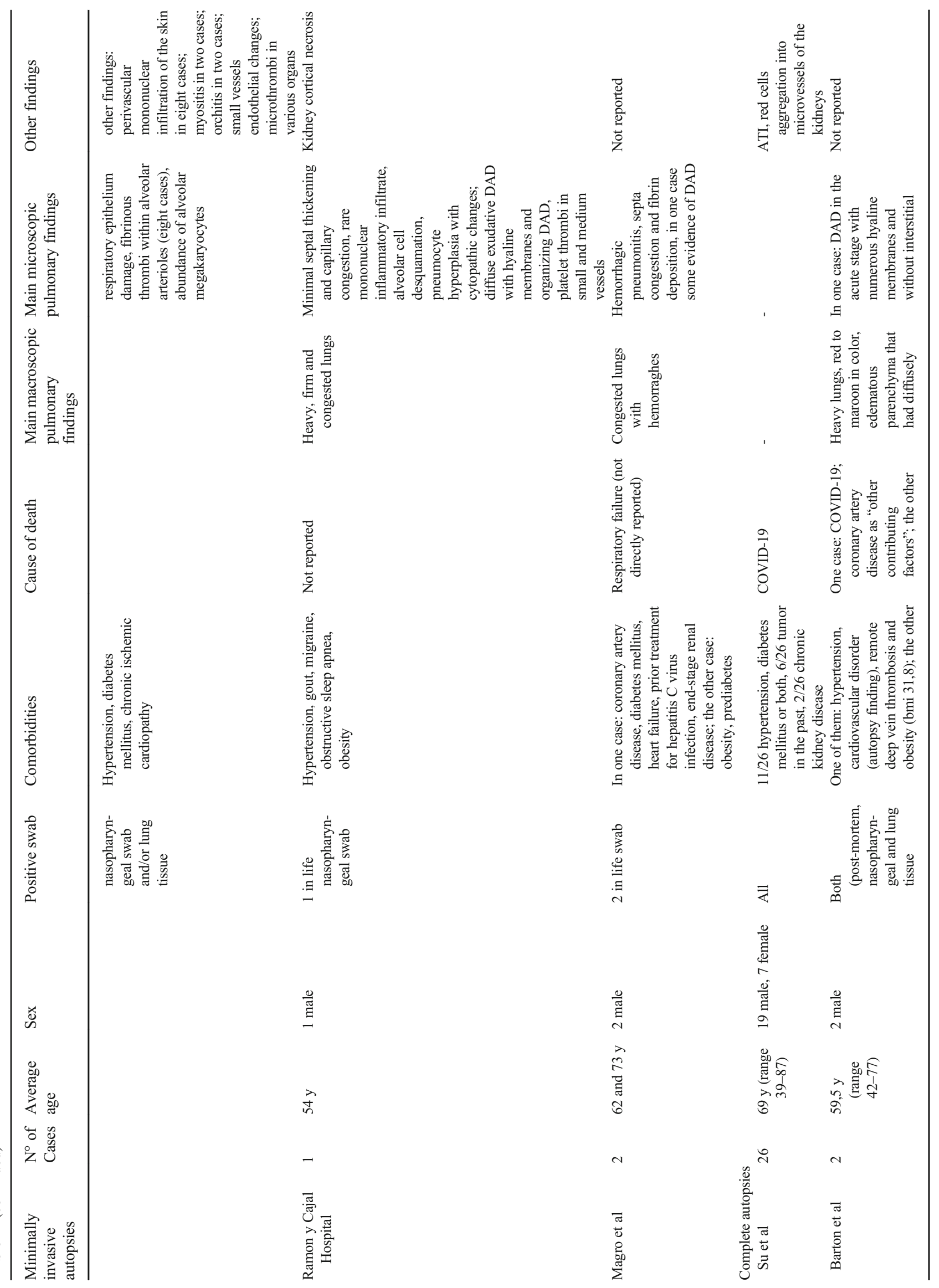




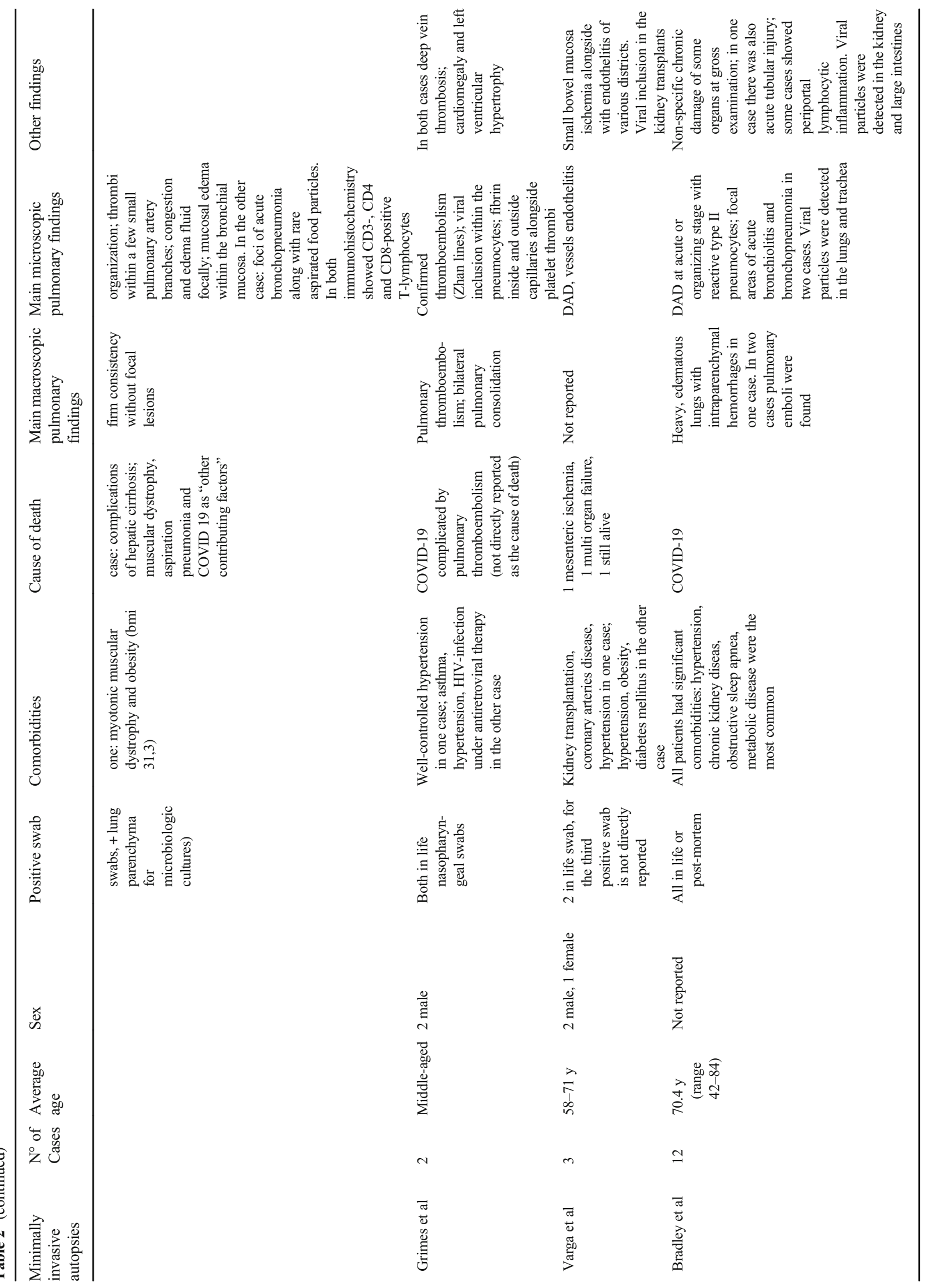




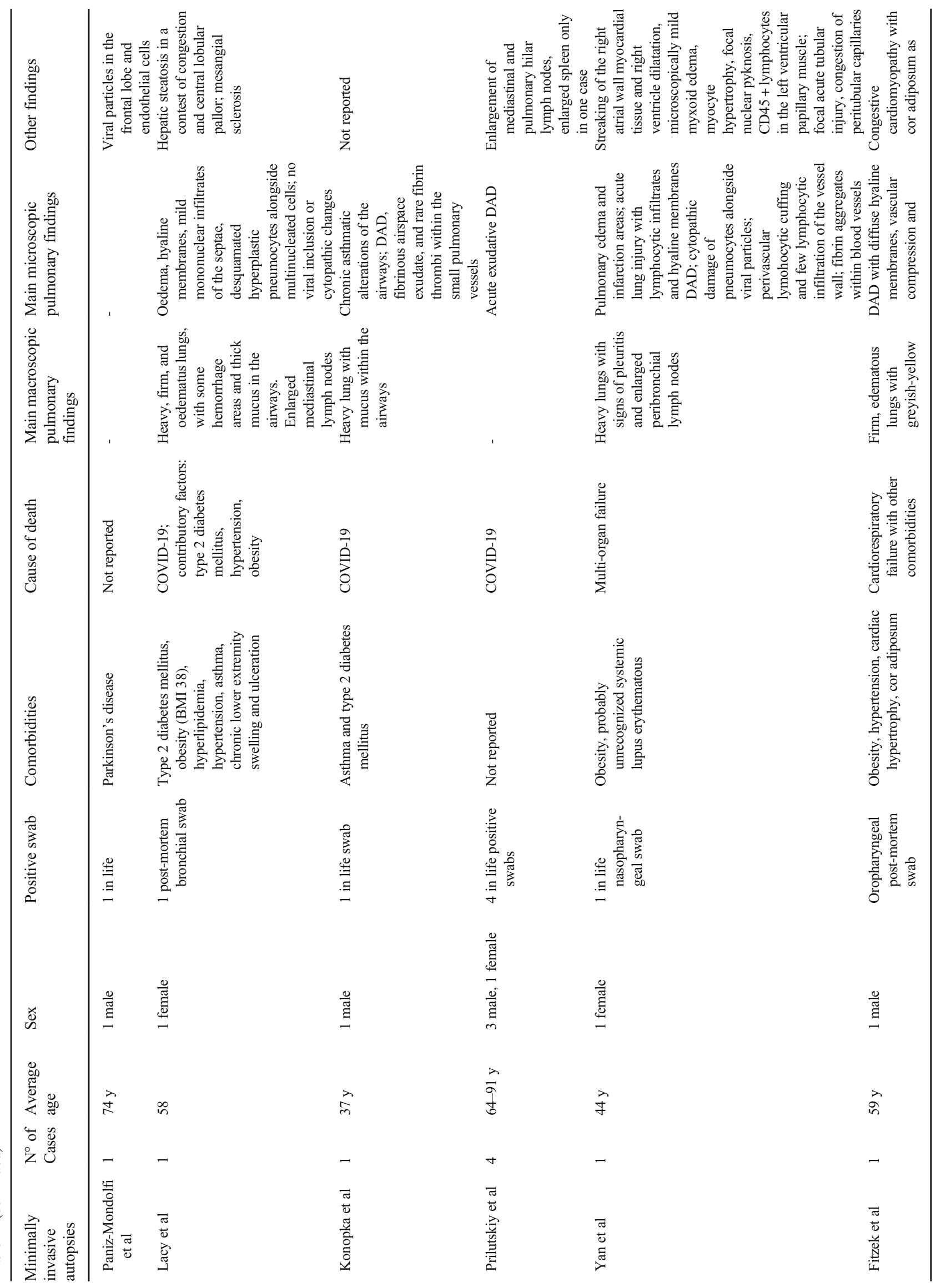




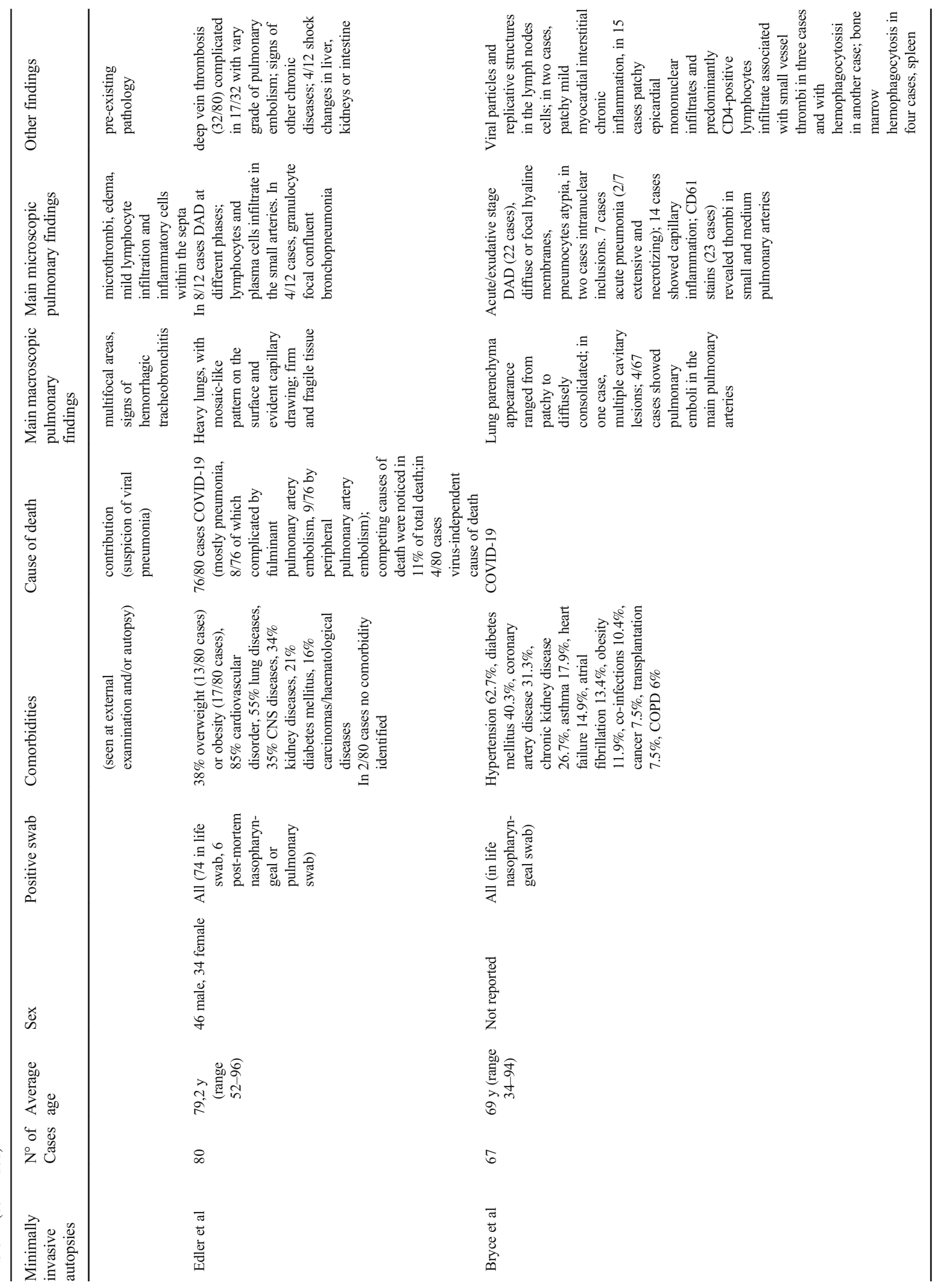




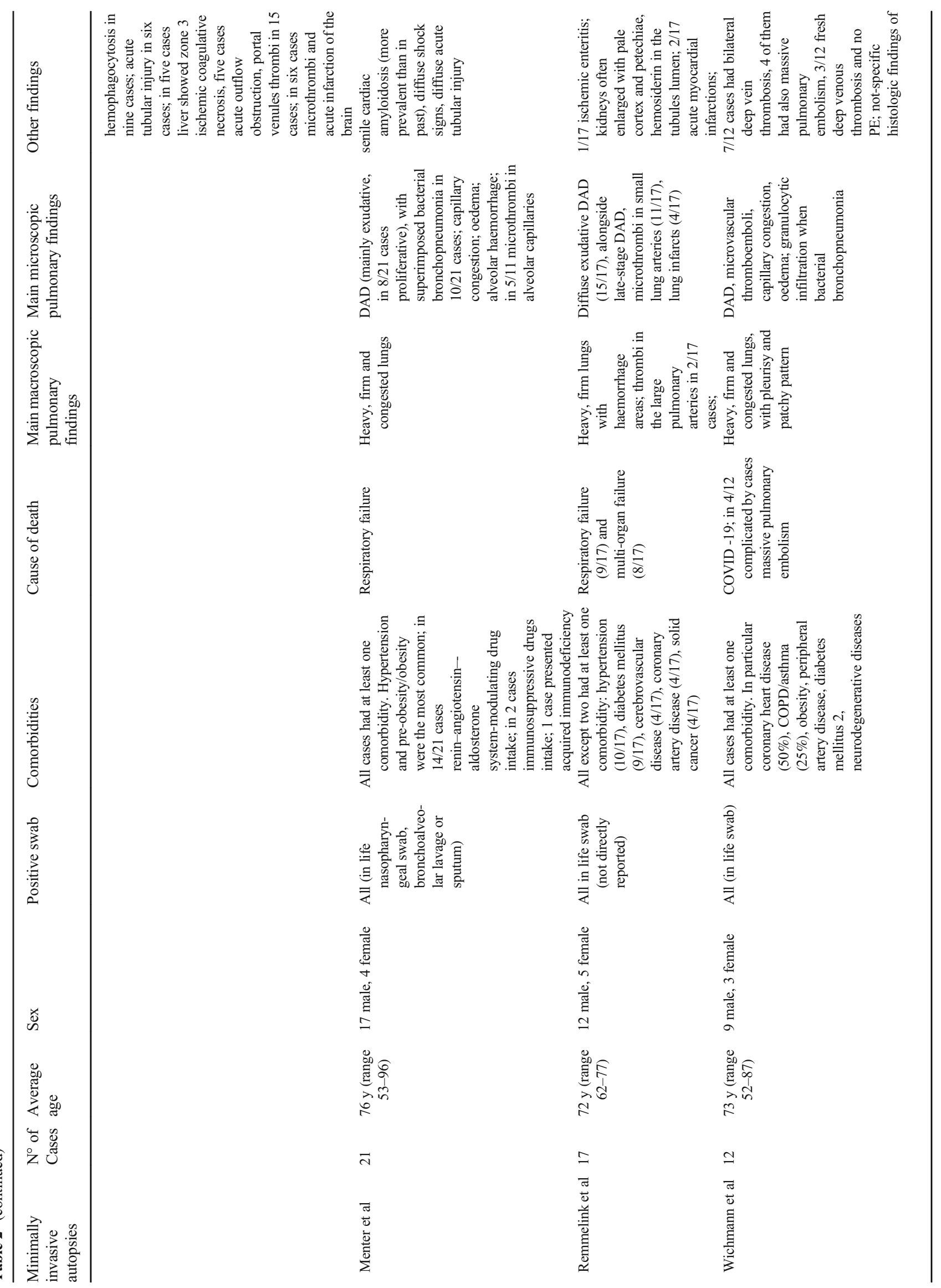








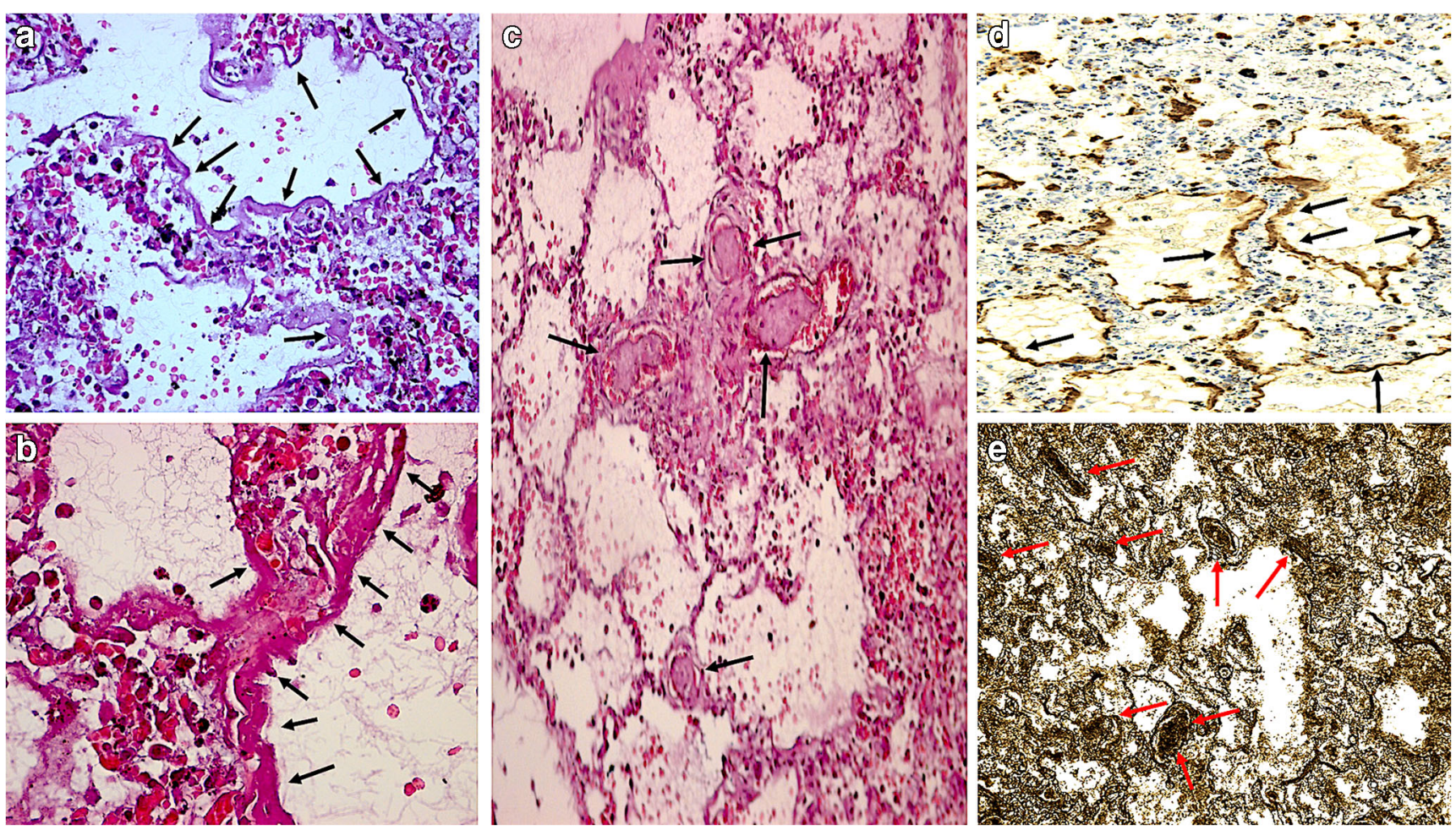

Fig. 2 Typical histological findings described in the literature: $\mathbf{a}-\mathbf{b}$ lung tissue showed edema, early stage DAD with hyaline membranes (arrows) and intraalveolar hemorrhages $(\mathrm{H} \& \mathrm{E}, \times 40, \times 100)$. c Lung:

an international COVID-19 postmortem diagnostic tool is required not only for gathering uniform autopsy and postmortem data, but also for facilitating comparisons of population and health care studies among states.

\section{Key Points}

1. At present, while the infection could still be considered as a health care emergency in many countries, knowing the pathophysiological mechanisms of COVID-19 is essential for correct therapy.

2. Despite attention to and investment in quantifying global burdens of disease, the diagnosis in the majority of Covid19 related deaths remain vague.

3. A literature review of the present evidence on postmortem examination of SARS-CoV-2 positive decedents highlights the main pathologic features of the disease.

4. A uniform COVID-19 post-mortem diagnostic protocol has not been proposed yet. In a time in which international collaboration is essential, standardized diagnostic criteria are fundamental requirements.

Funding Open access funding provided by Università degli Studi di Roma La Sapienza within the CRUI-CARE Agreement.

Open Access This article is licensed under a Creative Commons Attribution 4.0 International License, which permits use, sharing, microvascular thrombi (arrows) $(\mathrm{H} \& \mathrm{E}, \times 60)$, capillary congestion, and edema. DAD: d exudative phases (arrows) (Anti-Surfactant Protein A Antibody, $\times 40$ ) with microvascular thrombi (arrows) e (Weigert, $\times 20$ )

adaptation, distribution and reproduction in any medium or format, as long as you give appropriate credit to the original author(s) and the source, provide a link to the Creative Commons licence, and indicate if changes were made. The images or other third party material in this article are included in the article's Creative Commons licence, unless indicated otherwise in a credit line to the material. If material is not included in the article's Creative Commons licence and your intended use is not permitted by statutory regulation or exceeds the permitted use, you will need to obtain permission directly from the copyright holder. To view a copy of this licence, visit http://creativecommons.org/licenses/by/4.0/.

\section{References}

1. Wilson ME, Chen LH. Travellers give wings to novel coronavirus (2019-nCoV). J Travel Med. 2020;27:taaa015.

2. World Health Organization. Caronavirus disease (COVID-19). https://www.who.int/emergencies/diseases/novel-coronavirus2019. Accessed 08 Aug 2020.

3. Zhou F, Yu T, Du R, et al. Clinical course and risk factors for mortality of adult inpatients with COVID-19 in Wuhan, China: a retrospective cohort study [published correction appears in Lancet. 2020;395:1038]. Lancet. 2020;395:1054-62.

4. Salehi S, Abedi A, Balakrishnan S, Gholamrezanezhad A. Coronavirus disease 2019 (COVID-19): A systematic review of imaging findings in 919 patients. AJR Am J Roentgenol. 2020;215:87-93.

5. Zangrillo A, Beretta L, Scandroglio AM, et al. Characteristics, treatment, outcomes and cause of death of invasively ventilated patients with COVID-19 ARDS in Milan, Italy. Crit Care Resusc. 2020; [published online ahead of print, 2020 Apr 23]. 
6. Li X, Ma X. Acute respiratory failure in COVID-19: is it "typical" ARDS? Crit Care. 2020;24:198.

7. Huang C, Wang Y, Li X, et al. Clinical features of patients infected with 2019 novel coronavirus in Wuhan, China. Lancet. 2020;395: 497-506.

8. Maiese A, Passaro G, Matteis A, et al. Thromboinflammatory response in SARS-CoV-2 sepsis. Med Leg J. 2020;88:78-80.

9. Bassetti M, Vena A, Giacobbe DR. The novel Chinese coronavirus (2019-nCoV) infections: Challenges for fighting the storm. Eur J Clin Invest. 2020;50:e13209.

10. Kabashneh S, Ali H, Alkassis S. Multi-organ failure in a patient with diabetes due to COVID-19 with clear lungs. Cureus. 2020;12: e8147.

11. Devaux CA, Rolain JM, Raoult D. ACE2 receptor polymorphism: susceptibility to SARS-CoV-2, hypertension, multi-organ failure, and COVID-19 disease outcome. J Microbiol Immunol Infect. 2020;53:425-35.

12. Klatt EC, Nichols L, Noguchi TT. Evolving trends revealed by autopsies of patients with the acquired immunodeficiency syndrome. 565 autopsies in adults with the acquired immunodeficiency syndrome, Los Angeles, Calif, 1982-1993 [corrected - published correction appears in Arch Pathol Lab Med 1994;118:1200]. Arch Pathol Lab Med. 1994;118:884-90.

13. Franks TJ, Chong PY, Chui P, et al. Lung pathology of severe acute respiratory syndrome (SARS): a study of 8 autopsy cases from Singapore [published correction appears in Hum Pathol. 2004;35: 138]. Hum Pathol. 2003;34:743-8.

14. Sheng ZM, Chertow DS, Ambroggio X, et al. Autopsy series of 68 cases dying before and during the 1918 influenza pandemic peak. Proc Natl Acad Sci USA. 2011;108:16416-21.

15. Xu Z, Shi L, Wang Y, et al. Pathological findings of COVID-19 associated with acute respiratory distress syndrome. Lancet Respir Med. 2020;8:420-2.

16. Zhang $\mathrm{H}$, Zhou $\mathrm{P}$, Wei $\mathrm{Y}$, Yue $\mathrm{H}$, Wang $\mathrm{Y}, \mathrm{Hu} \mathrm{M}$, et al. Histopathologic changes and SARS-CoV-2 immunostaining in the lung of a patient with COVID-19. Ann Intern Med. 2020;172: 629-32.

17. Liberati A, Altman DG, Tetzlaff J, et al. The PRISMA statement for reporting systematic reviews and meta-analyses of studies that evaluate healthcare interventions: explanation and elaboration. BMJ. 2009;339:b2700.

18. Dolhnikoff M, Duarte-Neto AN, de Almeida Monteiro RA, et al. Pathological evidence of pulmonary thrombotic phenomena in severe COVID-19. J Thromb Haemost. 2020;18:1517-9.

19. Li G, Fox SE, Summa B, et al. Multiscale 3-dimensional pathology findings of COVID-19 diseased lung using high-resolution cleared tissue microscopy. bioRxiv. 2020; https://doi.org/10.1101/2020.04. 11.037473

20. Yao XH, Li TY, He ZC, et al. A pathological report of three COVID-19 cases by minimal invasive autopsies. Zhonghua Bing Li Xue Za Zhi. 2020;49:411-7.

21. Tian S, Xiong Y, Liu H, et al. Pathological study of the 2019 novel coronavirus disease (COVID-19) through postmortem core biopsies. Mod Pathol. 2020;33:1007-14.

22. Nunes Duarte-Neto A, de Almeida Monteiro RA, da Silva LFF, et al. Pulmonary and systemic involvement of COVID-19 assessed by ultrasound-guided minimally invasive autopsy. Histopathology. 2020. https://doi.org/10.1111/his.14160.

23. COVID-19 Autopsy. The first COVID-19 autopsy in Spain performed during the early stages of the pandemic. Rev Esp Patol. 2020;53:182-7.

24. Magro C, Mulvey JJ, Berlin D, et al. Complement associated microvascular injury and thrombosis in the pathogenesis of severe COVID-19 infection: a report of five cases. Transl Res. 2020;220: $1-13$.
25. Su H, Yang M, Wan C, et al. Renal histopathological analysis of 26 postmortem findings of patients with COVID-19 in China. Kidney Int. 2020;98:219-27.

26. Barton LM, Duval EJ, Stroberg E, Ghosh S, Mukhopadhyay S. COVID-19 autopsies, Oklahoma, USA [published correction appears in Am J Clin Pathol. 20205;153:852]. Am J Clin Pathol. 2020;153:725-33.

27. Grimes Z, Bryce C, Sordillo EM, et al. Fatal pulmonary thromboembolism in SARS-CoV-2-infection. Cardiovasc Pathol. 2020;48: 107227.

28. Varga Z, Flammer AJ, Steiger P, et al. Endothelial cell infection and endotheliitis in COVID-19. Lancet. 2020;395:1417-8.

29. Bradley BT, Maioli H, Johnston R, et al. Histopathology and ultrastructural findings of fatal COVID-19 infections in Washington State: a case series [published correction appears in Lancet. 2020;396:312]. Lancet. 2020;396:320-32.

30. Paniz-Mondolfi A, Bryce C, Grimes Z, et al. Central nervous system involvement by severe acute respiratory syndrome coronavirus-2 (SARS-CoV-2). J Med Virol. 2020;92:699-702.

31. Lacy JM, Brooks EG, Akers J, et al. COVID-19: Postmortem diagnostic and biosafety considerations. Am J Forensic Med Pathol. 2020. https://doi.org/10.1097/PAF.0000000000000567.

32. Konopka KE, Wilson A, Myers JL. Postmortem lung findings in a patient with asthma and coronavirus disease 2019. Chest. 2020;158:E99-101.

33. Prilutskiy A, Kritselis M, Shevtsov A, Yambayev I, Vadlamudi C, Zhao Q, et al. SARSCoV-2 infection associated hemophagocyticlymphohistiocytosis: an autopsy series with clinical and laboratory correlation. medRxiv. 2020. https://doi.org/10. 1101/2020.05.07.20094888

34. Yan L, Mir M, Sanchez P, Beg M, Peters J, Enriquez O, et al. COVID-19 in a Hispanic woman: autopsy report with clinical pathological correlation. Arch Pathol Lab Med. 2020. https://doi.org/10. 5858/arpa.2020-0217-SA.

35. Fitzek A, Sperhake J, Edler C, et al. Evidence for systematic autopsies in COVID-19 positive deceased: case report of the first German investigated COVID-19 death. Rechtsmedizin. 2020:1-6.

36. Edler C, Schröder AS, Aepfelbacher M, et al. Dying with SARSCoV-2 infection-an autopsy study of the first consecutive 80 cases in Hamburg, Germany. Int J Legal Med. 2020;134:1275-84.

37. Bryce C, Grimes Z, Pujadas E, et al. Pathophysiology of SARSCoV-2: targeting of endothelial cells renders a complex disease with thrombotic microangiopathy and aberrant immune response. The Mount Sinai COVID-19 autopsy experience. medRxiv. 2020. https://doi.org/10.1101/2020.05.18.20099960.

38. Menter T, Haslbauer JD, Nienhold R, et al. Postmortem examination of COVID-19 patients reveals diffuse alveolar damage with severe capillary congestion and variegated findings in lungs and other organs suggesting vascular dysfunction. Histopathology. 2020. https://doi.org/10.1111/his.14134.

39. Remmelink M, De Mendoca R, D'Haene N, De Clercq S, Verocq $\mathrm{C}$, Lebrun $\mathrm{L}$, et al. Unspecific post-mortem findings despite multiorgan 1 viral spread in COVID-19 patients. medRxiv. 2020. https://doi.org/10.1101/2020.05.27.20114363.

40. Wichmann D, Sperhake JP, Lütgehetmann M, et al. autopsy findings and venous thromboembolism in patients with COVID-19. Ann Intern Med. 2020. https://doi.org/10.7326/M20-2003.

41. Schaller T, Hirschbühl K, Burkhardt K, et al. Postmortem examination of patients with COVID-19. JAMA. 2020;323:2518-20.

42. Aguiar D, Lobrinus JA, Schibler M, Fracasso T, Lardi C. Inside the lungs of COVID-19 disease. Int J Legal Med. 2020;134:1271-4.

43. Fox SE, Akmatbekov A, Harbert JL, Li G, Quincy Brown J, Vander Heide RS. Pulmonary and cardiac pathology in African American patients with COVID-19: an autopsy series from New Orleans. Lancet Respir Med. 2020;8:681-6. 
44. Carsana L, Sonzogni A, Nasr A, et al. Pulmonary post-mortem findings in a series of COVID-19 cases from northern Italy: a two-centre descriptive study. Lancet Infect Dis. 2020. https://doi. org/10.1016/S1473-3099(20)30434-5.

45. Robert Koch Institute. Empfehlungen zum Umgang mit SARSCov-2-infizierten Verstorbenen. 2020. https://www.rki.de/DE/ Content/InfAZ/N/Neuartiges_Coronavirus/Verstorbene.html. Accessed 24 June 2020.

46. Indicazioni emergenziali connesse ad epidemia COVID-19 riguardanti il settore funebre, cimiteriale e di cremazione. Ministero della Salute-Direzione Generale Della Prevenzione Sanitaria. https://www.trovanorme.salute.gov.it/norme/ renderNormsanPdf?anno $=2020 \& \operatorname{codLeg}=73789 \&$ parte $=1 \%$ 20\&serie $=$ null. Accessed 24 June 2020.

47. Tian S, Hu W, Niu L, Liu H, Xu H, Xiao SY. Pulmonary pathology of early-phase 2019 novel coronavirus (COVID-19) pneumonia in two patients with lung cancer. J Thorac Oncol. 2020;15:700-4.

48. Luo W, Yu H, Gou J, Li X, Sun Y, Li J, Liu L. Clinical pathology of critical patient with novel coronavirus pneumonia (COVID-19). Preprints. 2020. https://www.preprints.org/manuscript/202002. 0407/v1.

49. Pernazza A, Mancini M, Rullo E, et al. Early histologic findings of pulmonary SARS-CoV-2 infection detected in a surgical specimen. Virchows Arch. 2020;1-6.

50. Peleg Y, Kudose S, D'Agati V, et al. Acute kidney injury due to collapsing glomerulopathy following COVID-19 infection. Kidney Int Rep. 2020;5:940-5.

51. Rossi GM, Delsante M, Pilato FP, et al. Kidney biopsy findings in a critically ill COVID-19 patient with dialysis-dependent acute kidney injury: a case against "SARS-CoV-2 nephropathy." Kidney Int Rep. 2020;5:1100-5.

52. Hanley B, Lucas SB, Youd E, Swift B, Osborn M. Autopsy in suspected COVID-19 cases. J Clin Pathol. 2020;73:239-42.

53. Osborn M, Lucas S, Stewart R, Swift B, Youd E. Autopsy practice relating to possible cases of COVID-19 (2019-nCov, novel coronavirus from China 2019/2020). The Royal College of Pathologists; 2020. https://www.rcpath.org/uploads/assets/d5e28baf-5789-4b0facecfe370eee6223/fe 8fa 85a-f004-4a0c-81 ee4b2b9cd12cbf/ Briefing-on-COVID-19-autopsy-Feb-2020.pdf. Accessed 24 June 2020

54. Basso C, Calabrese F, Sbaraglia M, et al. Feasibility of postmortem examination in the era of COVID-19 pandemic: the experience of a Northeast Italy University Hospital. Virchows Arch. 2020;1-7.

55. Fineschi V, Aprile A, Aquila I, et al. Management of the corpse with suspect, probable or confirmed COVID-19 respiratory infection - Italian interim recommendations for personnel potentially exposed to material from corpses, including body fluids, in morgue structures and during autopsy practice. Pathologica. 2020. https:// doi.org/10.32074/1591-951X-13-20.

56. Society of Pathological Doctors Chinese Medical Doctors Association, Chinese Society of Pathology, Chinese Medical Association. Provisional guidelines on autopsy practice for deaths associated With COVID-19. Zhonghua Bing Li Xue Za Zhi. 2020;49:406-10.

57. Mao DM, Zhou N, Zheng D, et al. Guide to the forensic pathology practice on death cases related to corona virus disease 2019 (COVID-19) (Trial Draft). Fa Yi Xue Za Zhi. 2020;36:6-5.

58. Santurro A, Scopetti M, D'Errico S, Fineschi V. A technical report from the Italian SARS-CoV-2 outbreak. Postmortem sampling and autopsy investigation in cases of suspected or probable COVID-19. Forensic Sci Med Pathol. 2020;16:471-6.

59. Tse GM, To KF, Chan PK, et al. Pulmonary pathological features in coronavirus associated severe acute respiratory syndrome (SARS). J Clin Pathol. 2004;57:260-5.

60. Ding Y, Wang H, Shen H, et al. The clinical pathology of severe acute respiratory syndrome (SARS): a report from China. J Pathol. 2003;200:282-9.

61. Ng DL, Al Hosani F, Keating MK, et al. Clinicopathologic, immunohistochemical, and ultrastructural findings of a fatal case of middle east respiratory syndrome coronavirus infection in the United Arab Emirates, April 2014. Am J Pathol. 2016;186:652-8.

62. Monteil V, Kwon H, Prado P, et al. Inhibition of SARS-CoV-2 infections in engineered human tissues using clinical-grade soluble human ACE2. Cell. 2020;181(905-13):e7.

63. Bonetti PO, Lerman LO, Lerman A. Endothelial dysfunction: a marker of atherosclerotic risk. Arterioscler Thromb Vasc Biol. 2003;23:168-75.

64. Lan J, Ge J, Yu J, et al. Structure of the SARS-CoV-2 spike receptor-binding domain bound to the ACE2 receptor. Nature. 2020;581:215-20.

65. Ferrario CM, Jessup J, Chappell MC, et al. Effect of angiotensinconverting enzyme inhibition and angiotensin II receptor blockers on cardiac angiotensin-converting enzyme 2. Circulation. 2005;111:2605-10.

66. Hamming I, Timens W, Bulthuis ML, Lely AT, Navis G, van Goor $\mathrm{H}$. Tissue distribution of ACE2 protein, the functional receptor for SARS coronavirus. A first step in understanding SARS pathogenesis. J Pathol. 2004;203:631-7.

67. Giannis D, Ziogas IA, Gianni P. Coagulation disorders in coronavirus infected patients: COVID-19, SARS-CoV-1, MERS-CoV and lessons from the past. J Clin Virol. 2020;127:104362.

68. Han H, Yang L, Liu R, et al. Prominent changes in blood coagulation of patients with SARS-CoV-2 infection. Clin Chem Lab Med. 2020;58:1116-20.

69. Guan WJ, Ni ZY, Hu Y, et al. Clinical characteristics of coronavirus disease 2019 in China. N Engl J Med. 2020;382:1708-20.

70. Puelles VG, Lütgehetmann M, Lindenmeyer MT, et al. Multiorgan and renal tropism of SARS-CoV-2. N Engl J Med. 2020. https://doi. org/10.1056/NEJMc2011400.

71. Inciardi RM, Lupi L, Zaccone G, et al. Cardiac involvement in a patient with coronavirus disease 2019 (COVID-19). JAMA Cardiol. 2020;5:1-6.

72. D'Ambruoso L, Boerma T, Byass P, et al. The case for verbal autopsy in health systems strengthening. Lancet Glob Health. 2017;5:e20-1. 